\title{
Domestication in C-E Subtitle Translation of American Empresses in the Palace from the Perspective of Skopos Theory
}

\author{
Li Ouyang \\ School of Foreign Languages, Southwest Petroleum University, Chengdu, China
}

\begin{abstract}
Recently, due to the influence of COVID-19 and the gradual deepening of cultural exchanges between China and the West, more and more audiences in the world choose to watch classic films and TV series at home. Chinese costume films and TV series are becoming more and more popular in western countries, while the subtitle translation plays a huge role in the spread of films and TV series. American Empresses in the Palace is a large-scale costume TV series widely praised by western audiences. Many of its subtitle translations adopt domestication strategies, making the subtitle more close to western audiences. Under the guidance of Skopos Theory, this paper takes the subtitle translation of American Empresses in the Palace as an example to discuss the practical application of domestication strategies in C-E subtitle translation, so as to further understand domestication strategies and provide more references for subtitle translation of other costume dramas.
\end{abstract}

Keywords: Subtitle translation, American Empresses in the Palace, Skopos Theory, Domestication.

\section{Introduction}

\subsection{American Empresses in the Palace}

As a costume drama, Chinese Empresses in the Palace is directed by Xiaolong Zheng, a very famous director in China. It depicts a lady who experiences many conspiracies and fights among concubines in the pursuit of love, and finally wields power of the whole palace after several ups and downs. And it was published by Beijing TV Art Center in 2011, which was made of 76 series, 45 minutes each episode, then the teleplay became more and more popular around the world.

In a context of Yong Zheng period, the teleplay Empresses in the Palace represents that Zhen Huan, a 17-year-old girl, takes part in the selection of imperial concubines with her sisters, Shen Meizhuang and An Lingrong. At the beginning, Zhen Huan does not mean to be selected, but the emperor Yong Zheng appreciates her wisdom and sedateness, so finally she is selected together with her sisters. After experiencing the arrogance of Consort Hua and abuse from other concubines, she generally becomes a shrewd lady in the palace. And then she fights against Consort Hua through accusing crimes of Nian Gengyao. But not for long, her families are secretly plotted by other officers and her father suffers the imprisonment. After that, Zhen Huan feels disappointed about the emperor, and she decides to practice Buddhism away from the palace. However, she meets her love Prince Guo Yunli, and then they have their own babies. But because of the emperor's order, Prince Guo has to be off at war. At that time, Zhen Huan has to go back to the palace to save her father, so she leaves Prince Guo Yunli. In the palace, although she keeps safe from the Empress' traps and even fight against her, she loses her real love Prince Guo Yunli. At the end, Zhen Huan becomes the Empress Dowager and owns lots of majesty, but she loses her love, families, sister and even to enemies, finally she stays alone in the end.

When American Empresses in the Palace headed to America, it arose strong concerns among fans. At this time, American professional team took the work of the translation which not only promised keep characteristics of original language maximally, but also rephrase sentences for American people. Then the American Empresses in the Palace was produced by a front-line team of films in USA, and was supervised by Yibin Lin together with Xiaolong Zheng. Furthermore, the former executive officer of Forbes Company Danielle Woodrew also took part in American Empresses in the Palace production team. After more than a year of serious editing, Empresses in the Palace had been adapted from the original 76 series into 6 series in all 90 minutes each episode. And then the teleplay was fully presented on a global scale.

\subsection{Language Characteristics}

After comparison and analysis, the author summarizes three outstanding characteristics of Chinese subtitles of Empresses in the Palace, namely formality, conciseness and the use of culture-loaded words.

\subsubsection{Formality}

Due to the limitation of feudal hierarchy, the dialogues between character in different identity are quite formal, the language is more written, even though the teleplay is about daily life in the imperial harem in ancient China, but many of the language is more formal, documented, even because of feudal society has a serious hierarchy, the people in the palace life also has a strict hierarchy and status, people of different status have great differences in tone and words. People of low status use honorific language when speaking to people of high status, while people of high status have higher freedom of speech. For example, in order to acquire the favor of the emperor, an older concubine deliberately wore a pink dress in front of the emperor, the emperor did not think it is proper for her to wear like this, but ironically said: "Pink is delicate, how old are you this year (粉色娇嫩, 你如今几岁)?” Hardly any other man in the palace would have dared say such a thing.

\subsubsection{Conciseness}


The dialogue between the main characters is succinct, it has a strong generality. The historical background of the play is the interlacing of the harem struggle and the politics of the time during the reign of Emperor Yongzheng in the Qing Dynasty. That is to say, in ancient China, vernacular Chinese did not appear, people read books in ancient Chinese, and wrote in ancient Chinese, such as writing letter, and even oral speaking also had many classical ancient Chinese features. And the leading roles in the TV series, both the emperor and his concubines, compared to the large number of the servants, they are at more honorable master position. According to social principles, usually people in a social low position talk more in mutual communication, and they need to pay attention to the style, tone, expression and some taboos. However, people in high social positions tend to use more concise and forceful language, they are more likely to make decisions and draw conclusions, and they are more educated, they are more likely to use highly condensed language and answer the key questions straightly.

\subsubsection{Culture-loaded words}

Chinese costume dramas contain the essence of Chinese culture and are rich in culture-loaded words. According to the plot, most of the concubines in the palace come from the families of the official, full of knowledge of classical poems and passages, and even proficient in piano, chess, painting and calligraphy, so their cultural accomplishment is relatively high, so the daily dialogue often mixed with some lantern riddles, drinkers' wager game, poetry and other phrases or sentences with Chinese characteristics. For example, when Zhen Huan appreciates the plum blossom in the snow, she wishes that if wind sees their strong will. Let such ordeal cease (逆风若解意, 容易莫摧残).

\section{Subtitle Translation}

\subsection{The Development of Subtitle Translation}

Subtitle translation is a new field of translation in China. After China's reform and opening up, a large number of foreign film and television works have been shown, broadcast and sold in China, resulting in the emergence of large-scale film and television translation activities. In recent years, with the rapid development of China's economy and the growing global influence of Chinese culture, Chinese films and TV dramas have gradually opened the Western market. As for the definition of subtitle translation, there are four representative opinions:

(1) Subtitling can be defined as the process of providing synchronized captions for film and television dialogue (and more recently for live opera)[1].

(2) Subtitles, sometimes referred to as captions, are transcriptions of film or TV dialogue, presented simultaneously on the screen[2].

(3) A subtitle is a printed statement or fragment of dialogue appearing on the screen between the scenes a silent motion picture or appearing as a translation at the bottom of the screen during the scenes a motion picture or television show in a foreign language[3].
(4) ...the words printed or superimposed on a film in a foreign language to translate what is being said on the sound $\operatorname{track}[4] \ldots$

Throughout the above definitions, the author believes that each definition has defined subtitle translation to some extent, but the explanation is not complete enough. Definition (1) points out that subtitle translation is the process of providing simultaneous explanations for dialogue between film and translation. Definition (2) is similar to definition (1), but the two definitions define the applicable scope of subtitle too narrowly. Firstly, it is limited to films and TV. In fact, any form of multimedia video can be subtitled if necessary. Second, subtitles do not necessarily only provide simultaneous explanations for the dialogue between the film and the TV. Subtitles can also explain and explain some non-dialogue texts. Definition (3) indicates that a subtitle is a printed explanation or illustration of another language displayed in a silent film scene or at the bottom of a film or television screen. This definition gives a more comprehensive explanation of the concept of subtitle. Definition (4) Translation of the language being spoken in the track from one language to another, printed or overlaid on film. Subtitle translation is not necessarily specific to the language being spoken.

\subsection{Characteristics of Subtitle Translation}

In this paper, it mainly involves three features of subtitle translation, which are popularity, instantaneity and interculturalness. Firstly, popularity means to organize simple sentences which can be easily understood by most audiences, and it has practical significance. So the subtitle translation appeared in the teleplay should accord with audiences' educational standard, and also translators should make subtitle translation popular and easy to understand. Secondly, instantaneity means that subtitle translation will disappear in a short time along with dialogues when it is showed on the screen. Usually, under the limitation of time and space, subtitle translation cannot add as many annotations as in books, so it needs to be concise and clear. Thirdly, it is known that language is a part of culture. But in reality, there are great cultural differences between Chinese audiences and foreign audiences. If translated one nation's history, cultures and customs in a literal way, it would cause misunderstandings among other audiences. And in Empresses in the Palace, it has many expressions with Chinese characteristics which also need a lot of consideration and processing. Thus, translators should fully consider audiences' cultural background and cognitive ability, and correctly understand cultural differences between original language and target language.

\section{An Overview of Skopos Theory}

\subsection{The Defication}

Skopos Theory is a concept from the field of translation studies. It provides an insight into the nature of translation as a purposeful activity, which is directly applicable to every translation project. It was established by the German linguist Hans Vermeer and comprises the idea that translating and interpreting should primarily take into account the function of both the source and target text. 


\subsection{The Development of Skopos Theory}

The development of Skopos Theory can be divided into four stages:

Firstly, in 1971, Katharina Reiss published Translation Criticism: The Potentials and Limitations, which marked the beginning of German functional theories of translation. "Taking equivalence as her basis, Katharina Reiss developed a model of translation criticism based on the functional relationship between source and target texts"[5]. However, she then found complete equivalence is unrealistic and even unnecessary, instead, translators need to consider the function of the source texts and the receivers of target texts, which can be seen as a foundation of Skopos Theory[6].

Secondly, Hans Vermeer published A Framework for a General Theory of Translation in 1978 to show his functionalist approach and break linguistic translation theory. Then, he proposed "Skopostheorie" in his article Skopos and Commission in Translational Action in 1989, which freed translation studies from the bondage of source-centered theory. Under this theory, translation is a purposeful behavior, and translators should determine the purpose according to the intended audience, considering their culture background, expectations and communicative needs[7]. Vermeer thought the Skopos rule should be the first considered rule, and he also believed that translators have initiative to adopt corresponding translation strategies according to different translation purposes.

Thirdly, in 1984, based on action theory, Justa Holz-Manttari wrote Theory of Translation Action, developing Vermeer's Skopos Theory further and proposing "translational action". She thought translation was a complex action designed to achieve a particular purpose, and paid much attention to participants in the process of translation[8].

Fourthly, Christina Nord published Translating as a Purposeful Activity in 1997. He summarized and improved all functional theories, using English to systemize internal and external factors needed to be considered when translating for the first time and how to determine translations strategies based on source texts. Additionally, she found shortcomings of Skopos Theory, so she proposed function plus loyalty principle to supplement Skopos Theory[9].

As the basic theory and main stream idea of German functionalism, Skopos Theory grew up from 1970s and was the core of functionalism translation theories. Skopos Theory believed that translation actions and essences was purposeful cross-cultural communication with the features of purposefulness, communicativeness and interculturalness.

According to Hans Vermeer, Skopos Theory includes three principles which are Skopos rule, coherence rule and fidelity rule. First, Skopos rule means that translation can integrate into the target language and its culture and then works in the way as the target groups might expect. Second, coherence rule believes that translation must cater to intratextual coherence, which can make translation become more readable, meaningful and acceptable in the process of cultural communication. Third, fidelity rule proposes that translation should be faithful to the text, and then remains the same with text. Nevertheless, Skopos rule is the prime one among these three principles, and coherence rule and fidelity rule should obey the Skopos rule. And also result determines method, which means the whole procedure should depend on the translation aims. As long as it achieves expected objectives, translation may not equal to the text. So the option of translation methods and strategies is based on the purpose of translation actions.

\section{Domestication Strategies and Application}

\subsection{Domestication}

Closely related to translation and cultural exchange, the translation should be how to deal with the cultural factors in the original text, diverse human culture, there must be differences between different cultures, sometimes the difference is very big, so how to spread this kind of difference, translation should use what kind of strategy to deal with this kind of difference, translation, insiders were divided, Some people think that translation should be Oriented toward Source Language Culture, while others think that translation should be Oriented toward Target Language Culture. Venuti distinguished two translation strategies in his book The Invisibility of the Translator, namely domesticating method and foreignization method. Domestication takes the target language or the target readers as its destination, making the author close to the readers. The translator should use the target language readers are used to express way to convey the content of the original, so the translator give a person illusion is not exist, echo the title of his book, the translator is invisible, and alienation in the source language into the guidance, to accommodate the language characteristics of foreign culture, to absorb foreign language expression, let the reader to be near the author, Venuti proposes, When translating into English, if the translation is restricted by many factors such as culture, the so-called faithful translation often needs to leave readers with a smooth appearance. Therefore, if alienated or experimental translation is adopted, the translator is likely to be resisted by publishers and others[10].

According to the analysis above, it believes that from the perspective of Skopos Theory, subtitle translation treats the aim as the highest principle, which means to choose different translation strategies on the basis of different translation aims and features. Moverover, Empresses in the Palace contains a lot of expressions with Chinese characteristics which represent some historical allusions, folk cultures, Chinese philosophies, so subtitle translation requires serious consideration. Nevertheless, foreigners have difficulty in understanding some expressions which contain deep historical cultural background, so it is necessary to adopt domestication in translation in order to enjoy films freely.

Domestication means to consider target language or audiences as objective and express text meaning in a way audiences expect, and then translate it into native language. Besides, there are many Chinese cultural factors in Empresses in the Palace, and it is difficult for foreign audiences to understand in a short time. So applying domestication strategy into subtitle translation and expressing the original to foreigners' level of understanding are necessary for them to freely enjoy 
films and appreciate Chinese cultures. And in subtitle translation of American Empresses in the Palace, there are four strategies of domestication, which are replacement, omission, interpretation and expansion.

\subsection{Application}

Domestication means to consider target language or audiences as objective and express text meaning in a way audiences expect, and then translate it into native language. Besides, there are many Chinese cultural factors in Empresses in the Palace, and it is difficult for foreign audiences to understand in a short time. So applying domestication strategy into subtitle translation and expressing the original to foreigners' level of understanding are necessary for them to freely enjoy films and appreciate Chinese cultures. And in subtitle translation of American Empresses in the Palace, there are four strategies of domestication, which are replacement, omission, interpretation and expansion.

\subsubsection{Replacement}

Replacement points that translation expressions substitute for the original ones, and mainly aims to solve translation problems of cultural factors. As growingly achievements in national intelligence, cultural image is endowed with the idea of cultural value, and also cultural intention is the most important one. It is known that film language is lively and vivid, and often expresses characters' emotion through inserting special native cultural images or metaphors. However, because of different living conditions and thinking modes, Chinese and American audiences may have different attitudes toward one cultural image. Furthermore, some special expressions in Chinese, once literally translated into English seemed to be arcane, but if translated in a free way, it would lose its language traits. So it can use replacement to substitute for the text through corresponding cultural image or expression of target language culture.

\section{Example 1: \\ 不知道有多少人盯着朕的这张龙椅。}

Heaven knows how many people have their eyes fixed on this throne.

This example shows that Emperor Yongzheng worries about his throne is robbed by others. Obviously, “龙椅” does not refer to a chair with a picture of dragon on it, while it means "throne". The reason is that dragon throne and dragon robe in ancient times always represent a symbol of supreme authority. However, the "throne" replaces the original “龙椅” in translation, that is because in western culture "throne" is also a symbol of kingship, so it shows different in approach but equally satisfactory in result. Besides, translating the first “不 知道” into "heaven knows" also caters to English habit. Thus, the replacement in this sentence greatly expresses the original meaning, which is a good example of Skopos Theory.

Example 2:

偏你这蹄子惊着眉姐姐的胎气。

Yet wretch that you are, you startled Mei and provoked her labor.
This example is that An Lingrong scolds her maid. The original “蹄子” refers to hoofs or legs of porks, it is also used as a disparaging term for women in ancient China. However, because of cultural differences between China and Wesstern countries, it can not be translated in a literal way. At this time, it uses "wretch" to express its meaning of bastard and scolding. Not only does it keeps the emotions, but also greatly shows the effects of the sentence and represents the principles of Skopos Theory.

Example 3:

你说这......太阳打哪出来了?

And pigs may well fly!

This sentence is organized by $\mathrm{Su}$ Peisheng when Shen Meizhuang who is mild and calm suddenly invites the Emperor for tea. In Chinese, “太阳打哪出来了” means something abnormal or goes in an unusual way. While in English "when pigs fly" also shows something is impossible or uncommon. It is known that idioms are used to express its own pragmatic effect, so the replacement here not only shows its metaphor, but also remains language vitality. The similar examples are as follows.

\section{Example 4:}

杀鸡是要儆猴的。

You would beat an offenseless dog to scare away a lion.

\section{Example 5:}

......却忘了树倒猢狲散。

... but you forget that even rats will abandon a sinking ship.

Example 6:

唇齿相依。

(The Third Prince and the Empress) are as closely united as hand in glove.

These three examples use the replacement of cultural image or expression, and involve similar expressions of target language to substitute the text instead of literal translation. Thus, it approaches the chief aim of subtitle translation, which is to make audience enjoy films freely. Furthermore, aims decide methods in the process of translation. Replacement conforms to target cultures and also shows the coherence rule.

\subsubsection{Omission}

Omission suggests that it concentrates text expressions on the promise of keeping the original detail, style and logicality, which means to simplify text with a minimum of original meaning lost. Skopos Theory emphasizes on reaction and feeling of target audience while subtitle translation tends to the process of translating spoken English into written words. During the process, deleting some redundant words makes it clearer to audience. In other words, omission compresses information that is unnecessary and reluctant to understanding in a limited time and space in order to emphasize the most important one.

Example 7:

敬天昌运 建中表正 文武英明 宽仁信毅 睿圣大孝 至诚宪 皇帝之墓 


\section{IN MEMORY OF THE YONGZHENG EMPEROR}

Posthumous title means that after some privileged figures' death, they will be given some titles with kind comment or critical idea, and all of them have their own meaning. So in the film when Emperor Yongzheng is dead, the posthumous title on his memorial tablet is not translated word by word. Instead, translators condense it into "IN MEMORY OF THE YONGZHEN EMPEROR", and even so it does not influence the understanding of the plot. On the contrary, it will be cumbersome and disperse audiences' attention. So the omission here can be able to American people and achieve cultural communication. Furthermore, omission also reflects on sentences which combine several Chinese phrases into one sentence in English.

Example 8:

说吧! 出了什么事? 这么乱哄哄。

Tell me what the commotion is about.

Example 9:

皇上, 祺贵人指使玢儿、斐雯与静白污荗臣妾。此事昭然 若揭。

Your Majesty, that Lady Qi induced Bin'er, Feiwen and Jingbai to slander me is now self-evident.

Both example 8 and example 9 are jointly translated into one sentence, and they are concise and do not lose original information. Besides, because of limitation of time and space, subtitle translation can not translate spoken dialogues word by word, so it is normal to omit and condense. Moreover, deleting some relatively secondary information does not influence the understanding of plots, it accords with Skopos rule and coherence rule.

\section{Example 10:}

那篗首上的合和二仙是多子多福, 如意双全之意。

The Gods of Harmony on the hairpin represent abundant fertility and good fortune.

In Chinese, “多子多福, 如意双全” symbolizes fertility and fortune. If it is translated literally, it will be "the more kids, the more blessings, just as you wish to own both". But comparing to the first translation, it is obviously sloppy although it expresses the original meaning.

\section{Example 11:}

那个时候我已经是贵妃了, 一人之下, 万人之上。

I was already a Noble Consort at that time in a lofty position.

“一人之下, 万人之上” can be explained that there is no one above me but the Emperor, while in literal translation it is "I have only one over me and millions under". However, American translation adapts the omission that is "in a lofty position". In this way, not only does it delete unnecessary information and make text brief and concise, but also becomes loyalty to text and caters to three rules of Skopos Theory.

\subsubsection{Interpretation}

There are explicit meaning and implicit meaning in texts, some are obvious to original audiences and do not need to explain, so they usually hide in sentences or cultural background behind words. But if so, it is difficult for foreigners to understand the implicit meaning of Chinese expressions or ellipsis expressions known by Chinese people, and then foreigners may be in a mass without any cultural preparation. Thus, it is essential to use interpretation in subtitle translation.

\section{Example 12:}

……温太医曾上门提亲, 不过不是当着老爷夫人面说的。 ... Doctor Wen did propose marriage. He did not propose formally.

Example 13:

来人！剥去她的贵妃服制！打入冷宫！

Now, strip off the emblems of her rank and send her to the Cold Palace.

In example (12), “提亲” is a culture-loaded word, which means to propose a marriage. But in ancient times, most Chinese girls get married under their parents' orders and by matchmakers' help. Traditionally, formal marriages should be allowed by parents，so “当着老爷夫人的面” can be translated into "formally". Instead, if it is translated into "in the presence of the parents", it may be difficult for American people to understand that why they must propose a marriage in the presence of parents. And in example (13), the status of Chinese concubines mainly depends on their dresses and customs, so it is normal to translate “贵妃服制” into “the emblems of her rank". From the above examples, it is known that interpretation is beneficial for Americans to understand and also it makes translation concise and frequent.

Example 14:

他尚且不能独善其身。

He was unable to preserve his good name.

In Mencius “独善其身” means the noble character who can keep his own style without any disturbance and live in the silt but not imbrued. In this sentence Wen Shichu persuades Zhen Huan not to participate in the selection in palace. So translators use "preserve his good name" to explain the idiom, it is easy for foreign audiences to understand.

Example 15:

娘娘虽然眼下失权, 倒能够明哲保身。

You have lost some power for now, but kept yourself from harm.

“明哲保身” refers to an attitude that in order to avoid struggle because of fear of being accused or charged, and also wise men are good at protecting themselves. At this point, Consort Hua blames Lady Cao for losing her power, but Lady Cao suggests her to seek self-insurance first. Here “明哲保身” is translated into "kept yourself from harm", it is clear for target audiences and also accords with their language customs.

\subsubsection{Expansion}

Expansion can amplify audiences' cognitive context. Because there are many poems, classical Chinese expression and some dialects in Empresses in the Palace, and so as to make 
foreigners to understand the connotation, it needs to expand and elaborate the translation. Besides, if the connotation is translated connotation in a literal way, it would break the coherence. So it needs to involve expansion in translation.

\section{Example 16:}

什么人在秋千上? 怎么见了咱们小主还不过来!

Who's there on the swing? Why didn't you come and forward to bow in respect?

\section{Example 17:}

就算哥哥曾经受过敦亲王的恩惠......

Though Duke Dun, the 10th prince, has helped him in the past...

In ancient times, concubines have different status, and the lower should bow down to the higher one. Thus, “过来” in example 16 is translated into "come and forward to bow in respect". And in example 17, "the 10th prince" shows his status, and it is easy for Americans to understand the plot.

\section{Conclusion}

It is known that subtitle translation plays an important role in cross-culture communication, but because of its own features, in the process of translation translators should seize translation aims. Skopos Theory gives theoretical basis for subtitle translation.

Besides, translators should fully consider audiences' cultural background and cognitive ability, and correctly understand cultural differences between original language and target language. So in order to communicate across cultures, translators should choose proper translation strategies depending on original text and get rid of the original form.

Based on Skopos Theory, this paper analyzes the subtitle translation of American Empresses in the Palace. Under the guidance, the teleplay subtitles involve domestication strategies to express information accurately and makes sure audiences well-understand the plots. So in the process of subtitle translation, translators should choose proper translation strategies according to various aims so as to produce high-quality works and promote cross-culture communication.

\section{References}

[1] Mark Shuttleworth, Moira Cowie. Dictionary of translation studies. Shanghai Foreign Language Education Press, Shanghai, 2004.

[2] M. Baker. Routledge Encyclopedia of Translation Studies, Routledge, New York, 2008.

[3] Merriam-Webste. Merriam Webster's Collegiate Dictionary Tenth Edition. Merriam-Webster, Incorporated, Springfield, 1997.

[4] R.E. Asher, O.J. Simpson. The Encyclopedia of Language and Linguistic Volume 8. Pergamon Press, Oxford, 1994.

[5] N. Christiane. Translating as a Purposeful Activity. St. Jerome Publishing, New York, 1997.
[6] R. Katharina. Translation Criticism: the Potentials and Limitations. St. Jerome Publishing, New York, 1971.

[7] V. Hans. Skopos and Commission in Translational Action. Helsinki: Oy Finn Lectura Ab., 1989.

[8] Manttari, J. Holz. Theory of Translation Action. Suomalainen Tiedeakatemia, Helsinki.1984.

[9] L.Q. Lv, H.Y. Zhu and P.Y. Ning. "Subtitle Translation of Foreign Movies and TV Series under Skopos Theory," Journal of Language Teaching and Research, Vol. 5, No. 4, 901-905, 2014.

[10] Venuti. "A History of Translation" in The Translator's Invisibility, Routledge, New York, 2008.

\section{Author Profile}

Li Ouyang received the B.A. degree in English from Shangqiu Normal University in 2019. She now is studying for Master Degree of Translation and Interpretation in Southwest Petroleum University. 